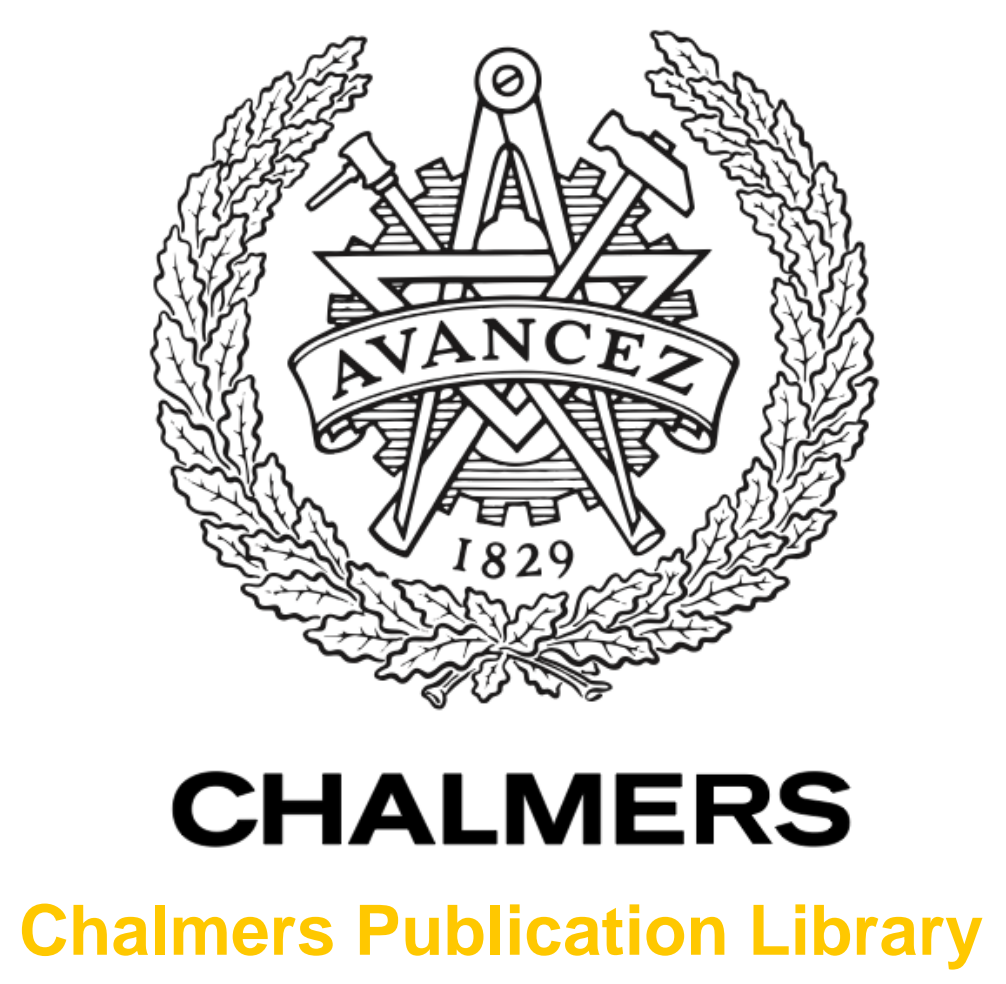

Evaluation of losses in microstrip gap waveguide for slot antennas applications

This document has been downloaded from Chalmers Publication Library (CPL). It is the author's version of a work that was accepted for publication in:

2012 IEEE International Symposium on Antennas and Propagation, Chicago, USA, July 814, 2012 (ISSN: 1522-3965)

Citation for the published paper:

Pucci, E. ; Rajo-Iglesias, E. ; Kildal, P. (2012) "Evaluation of losses in microstrip gap waveguide for slot antennas applications". 2012 IEEE International Symposium on Antennas and Propagation, Chicago, USA, July 8-14, 2012 pp. 1-2.

http://dx.doi.org/10.1109/APS.2012.6348596

Downloaded from: http://publications.lib.chalmers.se/publication/163388

Notice: Changes introduced as a result of publishing processes such as copy-editing and formatting may not be reflected in this document. For a definitive version of this work, please refer to the published source. Please note that access to the published version might require a subscription.

Chalmers Publication Library (CPL) offers the possibility of retrieving research publications produced at Chalmers University of Technology. It covers all types of publications: articles, dissertations, licentiate theses, masters theses, conference papers, reports etc. Since 2006 it is the official tool for Chalmers official publication statistics. To ensure that Chalmers research results are disseminated as widely as possible, an Open Access Policy has been adopted.

The CPL service is administrated and maintained by Chalmers Library. 


\section{Evaluation of Losses in Microstrip Gap Waveguide for Slot Antennas Applications}

\author{
Elena Pucci and Per-Simon Kildal \\ Department of Signals and Systems \\ Chalmers University of Technology \\ Gothenburg, Sweden \\ elena.pucci@ chalmers.se,per-simon.kildal @ \\ chalmers.se
}

\author{
Eva Rajo-Iglesias \\ Department of Signal Theory and Communication \\ University Carlos III of Madrid \\ Madrid, Spain \\ eva@tsc.uc3m.es
}

\begin{abstract}
The new microstrip gap waveguide supports a quasiTEM mode in the air by the use of artificial magnetic conductors which force the field to travel in the air rather than in the substrate. This paper presents an evaluation of losses by measuring the $Q$-factor of a resonator made in this technology, made using a mushroom-type EBG surface. Losses are crucial when using printed circuits to feed slot antennas, thereby motivating this work. Comparisons with standard microstrip lines will be provided, showing promising results.
\end{abstract}

\section{INTRODUCTION}

Printed slot antennas are of large interest nowadays for radar and communication systems due to their compact profile, low cost and easy manufacturing. In addition, they can be directly adapted to the fabrication of monolithic microwave integrated circuits (MMIC) [1]. However, losses in the microstrip feeding network are often the cause of gain limitations in antenna arrays [2]. Furthermore, cavity modes appear when packaging those circuits. The recently proposed ridge gap waveguide technology has demonstrated a good potential for applications at high frequency because of its low loss [3-5]. Its printed version, called microstrip gap waveguide, has been lately presented for packaging of microstrip components [6] and it is now considered as possible candidate for slot arrays applications. A parametric study of the mushroom dimensions on the parallel-plate stopband can be found in [7]. Therefore, this paper will go through the losses study, by calculating the attenuation from the measured Qfactor of a resonator made in this technology. The design of this gap waveguide version, shown in Fig. 1, permits the propagation in the air, thanks to the use of an artificial magnetic conductor, such as a mushroom-type EBG surface, which surrounds the microstrip line, forcing the field to travel in the air gap between the strip line and upper ground plane. The idea is that this solution can be used to feed slot antennas, located in the upper metal lid.

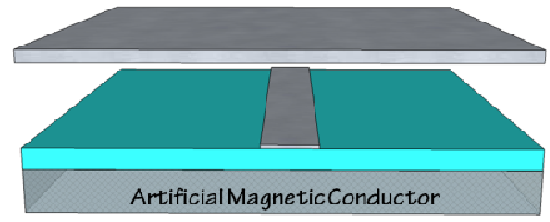

Figure 1. General sketch of a microstrip gap waveguide.

\section{LOSSES STUDY}

The losses study is done considering the design presented in [6] and shown in Fig. 2. The strip line is surrounded by mushrooms-type EBG, sharing the same substrate. The line is also short circuited to the ground plane with vias, to avoid leakage of field in to the dielectric, as shown in the color plots in Fig. 3. It can be seen that without vias on the strip line, a normal microstrip mode can be excited, between the strip and the lower ground plane, increasing losses.

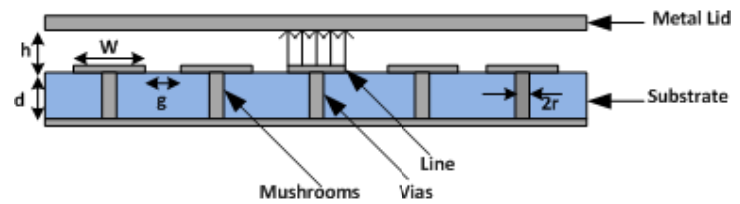

Figure 2. Front view of the microstrip gap waveguide on a mushroom-type EBG surface.

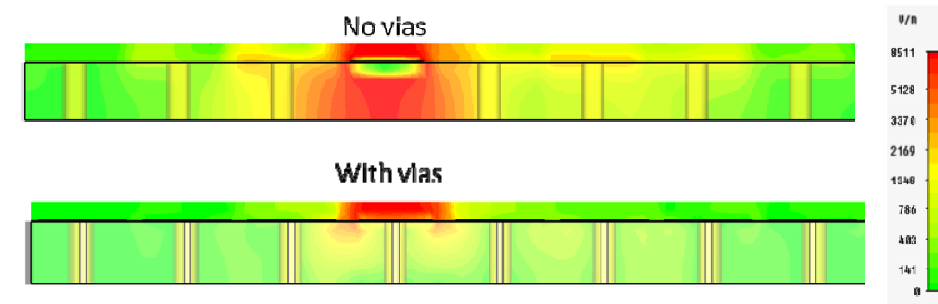

Figure 3. 2D color plots of the absolute vale of the E-field with no vias in the strip (first plot) and with vias added also in the strip (second plot).

Losses are determined by first calculating the unloaded Qfactor of the resonator. Then, the attenuation can be directly extracted by using the known formula [5] $\alpha=\beta \backslash 2 \mathrm{Q}_{\mathrm{U}}$ (with $\beta$ being the propagation constant). A resonator was manufactured and shown in Fig. 4. The strip line, of resonant length three times $\lambda / 2$, is printed at the center of the circuit and it is surrounded by mushrooms-type EBG. The choice of surrounding the line by mushrooms in all directions is to suppress any possible leakage of energy which can occur at the joints of the circuit, thus measuring the unloaded $\mathrm{Q}$ with a certain precision. The dielectric used is Duroid 5880, with ${ }_{\mathrm{r}}=$ 2.2 and $\tan \delta=0.0009$, and the metal is copper. Simulated and measured $S_{21}$ are presented in Figure 5. The unloaded Q can be calculated using the following equation [8], 


$$
Q_{U}=\frac{Q_{L}}{1-\left|S_{21}\right|}
$$

where $Q_{\mathrm{L}}$ can be directly determined from the $\left|\mathrm{S}_{21}\right|$ peaks, taking the ratio between the resonant frequency and the $3 \mathrm{~dB}$ power bandwidth. Using (1) the unloaded Q-factor is found to be 974 (at $f_{0}=9.743 \mathrm{GHz}$ ) from the simulated result and 765 (at $f_{o}=9.919$ ) from the measured result. The resulting loss is $\alpha$ $=0.9 \mathrm{~dB} / \mathrm{m}$ for the simulation and $\alpha=1.18 \mathrm{~dB} / \mathrm{m}$ for the measurement. The discrepancy between measured and simulated Qs could be due to the surface roughness, mechanical tolerances and impurities of the materials used. Also, the difference between simulated and measured resonant frequencies is because the strip was realized by via holes, whereas in simulation the vias are totally filled and this can affect the resonant lengths. For comparisons, the loss of a transmission line of thickness $\mathrm{t}=0.787 \mathrm{~mm}$, with same materials and resonant frequency used in this paper, can be easily calculated by analytical formula [5], obtaining 2.76 $\mathrm{dB} / \mathrm{m}$, proving how this new solution is less lossy than typical microstrip lines.

\section{CONCLUSIONS}

This paper presented a study of microstrip gap waveguide made with a mushrooms-type EBG surface in terms of losses. The structure has low loss due to its propagation in the air and it does not generate cavity modes when packaged, compared to standard microstrip lines, becoming a promising candidate to feed slot antenna arrays. Fig. 5 shows a possible antenna design, with the slot located on top of the metal lid, which will be considered as next step of this work.

\section{ACKNOWLEDGEMENT}

This work has been supported by the Swedish Research Council VR and by the Spanish project TEC2009-14525-C0201 .

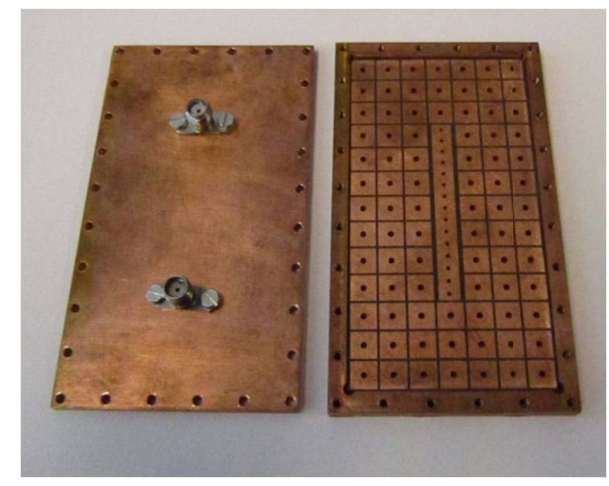

Figure 4. Microstrip gap waveguide resonator prototype.

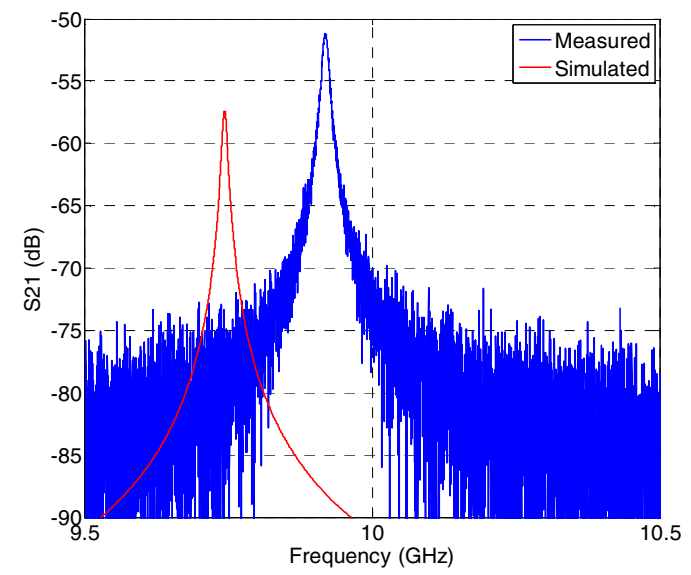

Figure 5. Simulated and measured $\left|\mathrm{S}_{21}\right|$ for the resonator made in microstrip gap waveguide.

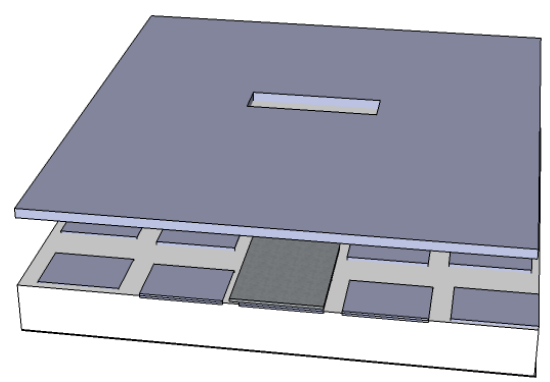

Figure 6. Sketch of a slot antenna fed by the microstrip gap waveguide.

\section{REFERENCES}

[1] K.-L. Wong, Compact and broadband microstrip antennas, Wiley, New York, 2002.

[2] G. R. James, P. S. Hall, and C. Wood, "Microstrip Antenna Theory and Design," London: Peter Peregrinus, ch 5, 6, 1981.

[3] P.-S. Kildal, E. Alfonso, A. Valero-Nogueira, E. Rajo-Iglesias, "Local metamaterial-based waveguides in gaps between parallel metal plates", IEEE Antennas and Wireless Propagation Letters, Vol. 8, pp. 84-87, 2009

[4] P. S. Kildal, A. U. Zaman, E. Rajo-Iglesias, E. Alfonso, and A. ValeroNogueira, "Design and experimental verification of ridge gap waveguide in bed of nails for parallel-plate mode suppression", IET Microwaves, Antennas \& Propagation, vol. 5, no. 3, pp. 262-270, 2011.

[5] E. Pucci, A. U. Zaman, E. Rajo-Iglesias, P.-S. Kildal and A. A. Kishk, "Losses in ridge gap waveguides compared with rectangular waveguides and microstrip transmission lines", 4th European Conference on Antennas and Propagation, EUCAP 2010, Barcelona, Spain, 11-16 April 2010.

[6] E. Pucci, E. Rajo-Iglesias, and Per-Simon Kildal, "New microstirp gap waveguide on mushroom-type EBG for packaging of microwave components", accepted for publication in IEEE Microwave and Wireless Components Letters, Dec. 2011.

[7] E. Rajo-Iglesias, P.-S. Kildal, "Numerical studies of bandwidth of parallel plate cut-off realized by bed of nails, corrugations and mushroom-type EBG for use in gap waveguides", IET Microwaves, Antennas \& Propagation, Vol. 5, No 3, pp. 282-289, March 2011.

[8] J. Papapolymerou, C. Jui-Ching, J. East, and L. P. B. Katehi, "A micromachined high-Q X-band resonator," IEEE Microwave and Guided Wave Letters, vol. 7, no. 6, pp. 168-170, 1997. 